\title{
Wages or Fringes? \\ Some Evidence on Trade-offs and Sorting*
}

\author{
Tor Eriksson \\ Aarhus School of Business, Aarhus University, tor@asb.dk \\ Nicolai Kristensen \\ Danish Institute for Governmental Research and IZA, nik@akf.dk
}

January 2011

\begin{abstract}
The two key predictions of hedonic wage theory are that there is a trade-off between wages and nonmonetary rewards and that the latter can be used as a sorting device by firms to attract and retain the kind of employees they desire. Empirical analysis of these topics are scarce as they require detailed data on all monetary as well as nonmonetary rewards, not only for the job chosen but also for alternative offers. In this paper this data predicament is solved by the use of the vignettes method to estimate individuals' willingness to pay for fringe benefits and job amenities. We find clear negative wage-fringe trade-offs, considerable heterogeneity in willingness to pay for fringe benefits, and signs of sorting. The findings imply that personnel economics models can be applied also to the analysis of nonmonetary rewards.
\end{abstract}

JEL Classification: J32, J33, M52

Keywords: Fringe benefits, Nonmonetary rewards, Trade-off, Sorting, Heterogeneity

${ }^{*}$ We thank Kenneth Train, participants at the annual CCP workshop in Kolding and seminar participants at Aarhus School of Business, Aarhus University and WISE, Xiamen University for helpful comments. Financial support from the Nordic Center of Excellence in Empirical Labour Economics is gratefully acknowledged. 


\section{Introduction}

For this paper we collect data which allow us to estimate employees' Willingness-to-Pay (WtP) for nonpecuniary benefits. The aim of our study is threefold. First, to empirically investigate whether the expected trade-off exists, and second whether or not there are any signs of sorting. In addition to demonstrating the trade-off between pay and individual fringes and amenities, we also examine the extent to which employees differ in their WtP for nonpecuniary benefits. This information is important for employers in deciding on the design of compensation packages. Furthermore, our analysis informs us about differences in the WtP for different "quantities" of the fringes. Third, this paper also seeks to demonstrate that this relatively simple tool-kit can be used in larger organizations or across smaller enterprises, and may assist managers in putting together more efficient compensation packages, given any special needs they may have. Efficiency is a cornerstone in personnel economics (Lazear and Oyer, 2010), and the vignettes method has the potential to provide companies with a tool to detect possible inefficiencies and hence to increase profits.

The inclusion of nonmonetary benefits and job amenities as important parts of employees' compensation packages has proliferated across many countries in recent years, see e.g. annual reports from Society for Human Ressource Management. From an economic perspective providing nonmonetary benefits can be rational behavior on the part of both employer and employees for three reasons. First, exploiting scale economies employers can sometimes acquire these goods at a lower cost than single employees. Occasionally, the fringe benefits may also be taxed less heavily than income from work. Second, including nonpecuniary benefits in compensation packages can also act as a sorting device to attract and retain key employees (Oyer, 2008). Still a third way of thinking about nonmonetary compensation, common in industrial psychology studies, is to consider nonmonetary rewards as status and identity aspects of a job or position, and as complementary rather than as substitutes for monetary rewards (Milkovich and Newman, 2010). 
Given the prevalence of benefits it is natural to ask how employers should use fringe benefits and nonmonetary rewards. Should they use cafeteria plans, that is, offer their employees a menu of possible benefits? Or should they apply more precisely targeted benefits? The hedonic model of compensation (Rosen, 1974), provides a useful analytical framework to understand the relevant mechanisms.

In designing its compensation policies, including nonpecuniary benefits, the firm faces two choices. The first choice is to select benefits that provide incentives for workers to perform better, i.e. productivity enhancing benefits, such as pension systems that encourage human capital investments or working time flexibility arrangements which lower employees' cost of effort. The difficulty here is that since benefits are costly, the employer needs to weigh the productivity gain to the increase in costs. In this setting, a tradeoff arises as the hedonic model predicts a negative trade-off between wages and nonmonetary rewards like flexibility, home-pc or company car.

The second choice is about finding combinations of pay and nonmonetary benefits that attract the kind of workers the firm desires. How many and which kind of nonmonetary benefits the firm will offer is consequently the outcome of the interaction of workers' preferences, the firm's cost structure and desire to attract specific types of labor. The key insight offered by the hedonic model is that fringe benefits and nonmonetary compensation can be used actively as a sorting device. Carefully designed, a compensation package may induce the type of applicants, which the employer wants, and concurrently screen-out applicants that do not fit the desired profile of the workplace.

Although these principles are widely recognized as efficient behavior by rational agents, there is relatively little empirical evidence.

First, it has proven rather difficult to provide evidence of the trade-off between monetary and nonmonetary benefits predicted by the hedonic utility model, see e.g. Brown (1980), Duncan and Holmlund (1983) and Gronberg and Reed (1994), Oyer (2008). The main reason for the difficulties involved is that it is virtually impossible to gather field data that allow for this type of estimation. Consider the sort of data needed to test for a negative trade- 
off between benefits and pay. Not only should we observe an employee's current compensation package in the job she has chosen, and she has been chosen for, but we also need to observe alternative offers she may have received. Moreover, one needs to control for the employee's observable as well unobservable skills as these are likely to be positively correlated with both the monetary and nonmonetary rewards received by the employee. Obviously, neither register nor survey data are likely to contain this information. Using job offers given to postdoctoral biologists, Stern (2004) provides one important exemption for the lack of suitable data, and finds that, indeed, scientists do pay to be scientists.

Second, there is even less evidence available on the extent to which compensation packages serve as sorting mechanisms. The seminal paper by Salop and Salop (1976) focuses on different forms of compensation as a means to induce the most productive workers to join the firm. Oyer's (2008) theoretical model is concerned with the use of benefits to sort employees based on their tastes. His empirical analysis, which is based on individuals' selfreported benefit eligibility information (NLSY), shows that employees who are likly to value certain benefits (employer provided meals and dental and health insurance) more, are employed at firms providing them.

A key novelty of this paper is the type of data we exploit to estimate WtP for the nonpecuniary aspects of compensation packages. We use survey data and ask respondents to choose between two fictive jobs described in so-called vignettes. The vignette method has earlier been used extensively in other fields but rarely in labor economics. Early studies appeared in marketing research (Green and Rao 1971, Green and Srinivasan, 1978), while transport economics (Ben-Akiva et al., 1993), and environmental and resource economics (Adamowicz et al., 1998) are examples of disciplines within the economic realm that have used this approach. In labor economics, van Beek et al. (1997) also make use of vignettes although their objective differs from ours. To the best of our knowledge, this is the first time vignettes are applied in the context of eliciting individuals' Willingness-to-Pay for fringe benefits.

The personnel economics literature has contributed to a better understanding of a wide range of questions related to human resource management 
practices, such as teamwork, promotions, incentive pay and the use of fringe benefits; see Lazear and Shaw (2007), Lazear and Oyer (2010) and Oyer and Schaefer (2010) for recent overviews. If it can be shown empirically that there is a negative trade-off between nonmonetary rewards and wages, and that sorting does matter, this will be an important finding as it implies that all the models in personnel economics apply not only to monetary rewards but also to nonmonetary rewards.

Previewing our main findings, they are briefly as follows. First and foremost, we find clear evidence of negative wage-fringe benefit trade-offs. Moreover, the analysis documents large differences in how individuals value fringe benefits. We find considerable differences in willingness-to-pay for fringe benefits both within and between demographic groups. When comparing individuals' willingness-to-pay for specific benefits with whether they receive them in the jobs they currently hold, we observe fairly strong positive relations suggesting that employers use compensation packages as a means of sorting of their employees.

The remainder of this paper unfolds as follows. In the next section we briefly discuss the hedonic wage model. Section 3 includes a description of vignettes and the sample of respondents are given. Section 4 presents the econometric method employed and the fifth section gives the empirical results. Section 6 contains a discussion of the economic implications of our findings and section 7 concludes.

\section{The Hedonic Compensation Model}

The hedonic compensation model described in Rosen's (1974) seminal analysis focuses mainly on the cost side of fringe benefits and job attributes. The key trade-off in the analysis is between benefits and pay, i.e., the balance between offering more benefits and less pay. In the simplest possible model, workers are assumed to have identical preferences regarding benefits. As these, like wages, are goods, the trade-off can be described by means of a downward-sloping convex indifference curve in benefit and wage space. Once a firm knows the slope of the indifference curve it can choose the 
correct combination of wage and benefit offers.

Allowing for heterogeneous preferences, that is, acknowledging the fact that different individuals place different weights on benefits and wages, makes things more complicated. A simple example is offered by Lazear (1998) and reproduced in Figure 1.

\section{[Figure 1 about here]}

Imagine two employees: one is a chess player during his leisure time and the other likes to windsurf. Windsurfing depends on the weather and the windsurfer therefore places more value on flexible working time vis-à-vis the chess player. This is shown in Figure 1 where the windsurfer is more willing to trade-off wage earnings for flex-time compared to the chess player.

Thus, hedonic compensation theory tells us that willingness to pay for fringe benefits and job amenities varies with employee type, and that firms can try to make the workers it desires self-sort as employees to the firm by choosing appropriate wage-benefit combinations.

\section{Data}

Data were collected through an internet based survey launched in May 2009 on a panel of Danish respondents. ${ }^{1}$ In order to have a sample of respondents who were likely to hold jobs and to receive job offers where remuneration potentially includes fringe benefits and other nonmonetary rewards, five sample selection criteria were utilized. The respondent should:

- have completed high school or higher education.

- be in the age range 25 to 64 .

- $\quad$ be employed, i.e., we exclude students, self- and unemployed.

- $\quad$ work minimum 30 hours per week in her main occupation.

- $\quad$ not be employed in the primary sector, e.g., in farms, fisheries.

- $\quad$ not be a CEO or a top level manager.

\footnotetext{
${ }^{1}$ The panel of potential respondents is kept by the private survey institute YouGovZapera, which also undertook the data collection.
} 
An invitation to participate was sent out to 10,000 members of the respondents panel; 6,300 responded of which 3,094 matched our selection criteria.

Given this screening procedure it is not surprising that the final sample contains relatively many highly educated respondents - more than 50 percent have 3-4 years of college or higher education. ${ }^{2}$ The corresponding share in the overall Danish population is about 25 percent. Consequently, the mean gross monthly income is also high, about 35,000 DKK (6,400 USD) as compared to the population mean of about 22,000 DKK (4,000 USD). ${ }^{3}$ The female labor participation rate is high in Denmark; nevertheless, the 51 percent female share in the sample is also above the population share of 47 per cent females in the workforce. In the econometric analysis we limit the sample to individuals who work between 30 and 73 hours per week.

\subsection{The Vignettes}

Although the intuition is clear - there is likely to be a trade-off between fringe benefits and wages - it has proven very hard to verify this claim empirically. A data-predicament arises from the fact that we rarely observe employees' compensation packages and we virtually never observe what they alternatively could have chosen, i.e. their outside options.

Here, we solve this problem by building vignettes, in which respondents are offered a series of fictive choices between two alternating jobcompensation packages. Faced with two job-compensation packages, A and $\mathrm{B}$, the respondent is asked to choose one for the other and this exercise is repeated 7 times per respondent, each time with different values for the variables that characterize the job-compensation package.

\footnotetext{
${ }^{2}$ See Table B1, Appendix B for a list of average, min and max of the variables included in the data set.

${ }^{3}$ We here use the exchange rate as of May 2009 where one USD $=5,464$ DKK. Note that the min and max columns reveal some extreme outliers. They are deleted from the regression analyses. We choose to delete the top and bottom percentile of the income distribution. This yields an average monthly income of 32,868 DKK $(6,015)$ and minimum of 13,000 DKK (2,380 USD) and maximum of 100,000 DKK (18,300 USD). Given the very compressed income distribution in Denmark these remain rather extreme values (note that we also excluded self-employed, CEO's and other top level managers).
} 
To flesh out the idea further, consider the example given in Figure 2 below. A vignette in the left column includes all attributes describing the job. These attributes do not change between vignettes but their values change between choice situations. This yields variation in the data that allows us to identify parameter values. In order to induce a high degree of variation in the possible combinations 70 different vignettes were applied. See Appendix A for further details on the introductory text and attribute levels.

[Figure 2 about here]

In the example given in Figure 2, the respondent may choose Job A in which she is offered a complete health insurance - something the alternative, Job B, does not offer. However, opting for the health insurance comes at a cost since Job $\mathrm{B}$ offers a higher wage ( $5 \%$ more than Job A), 5 days of training per year and flexible work hours. In the example, two of the attributes, "Home-pc + ADSL internet" and "Annual bonus (equivalent to one month's pay)" are held constant across the two alternatives. In other vignettes these could vary while, typically, one or more of the other attributes would then be held constant.

\subsection{Data Description}

For the purpose of this paper we are especially interested in the amount of fringe and job amenities each employee receives in her current job as we examine whether there are any signs of sorting. About three out of four respondents, 73 percent, did not receive a bonus in 2008, see Table 1 . This is well in accordance with the survey evidence of firms in the European Company Survey (2009) and a survey of exclusively Danish firms, Eriksson (2010), carried out in the same year.

[Tables $1 \& 2$ about here]

Despite the uniform coverage of free public health in Denmark, demand 
for private health insurance has recently grown markedly - mainly as a result of long waiting lists in the public health care sector. Consequently, about 35 percent of the respondents have some type of private health insurance, see Table 2. The most common and least costly fringes are free coffee and fruit, whereas the most costly, company cars, are relatively rare (only 4 percent). ${ }^{4}$

Employer provided training is among the job amenities investigated in this paper. As can be seen from Table 3, about 15 percent never received training while an additional 25 percent had not received employer provided training in the current year, but had so in previous years. Among respondents who received some training in 2008, most had been in training for less than two weeks. ${ }^{5}$

[Table 3 about here]

\section{Econometric Framework for the Hedonic Model}

The starting point for estimating Willingness to Pay $(W t P)$ for job attributes is a simple utility function, $U$,

$$
U_{n j t}=\beta_{n} x_{n j t}+\varepsilon_{n j t}
$$

where utility from alternative $j$ in choice situation $t$ for individual $n$ is given by equation (1). $\beta$ is a parameter vector and $x$ is a matrix that includes vignette characteristics and background variables interacted with vignette characteristics. The coefficients $\beta_{n}$ are distributed with density $f(\beta \mid \theta)$, where $\theta$ refers to the mean and covariance of $\beta$. The error term $\varepsilon_{n j t}$ is

\footnotetext{
${ }^{4}$ Most prevalent in the "other" category are "free lunch", newspaper, employee shares and products from the company.

${ }^{5}$ These numbers are very much in line with those found in a major Danish survey conducted in 2006, see Trepartsudvalget (2006). The share of employees in the entire population who never received training is higher than 15 percent since employees with no high school degree (not included here) tend to have a relatively lower training propensity.
} 
assumed to be iid extreme value distributed over time, people and alternatives. This is the mixed logit model with a continuous mixing distribution, see Revelt and Train (1998), Train (2003), which can be estimated using simulated maximum likelihood. The coefficient vector can be expressed as $\beta_{n}=b+\eta_{n}$, where $b$ is the population mean, and $\eta_{n}$ is individual $n$ 's stochastic deviation from the average in the population. The estimated utility function can now be expressed as $U_{n j t}=b_{n}^{\prime} x_{n j t}+\eta_{n}^{\prime} x_{n j t}+\varepsilon_{n j t}$. The stochastic part $\left(\eta_{n}^{\prime} x_{n j t}+\varepsilon_{n j t}\right)$ can be correlated over alternatives and time, and therefore this model allows for very general patterns of substitution between alternatives. ${ }^{6}$

An estimate of the Willingness-to-Pay is usually obtained by dividing a parameter for a given characteristic with a cost parameter; see Revelt and Train (1998). In this application, we use the wage-parameter as the implicit "cost". The idea is to estimate WtP for nonmonetary rewards, which in turn enables us to answer questions of the following type: How much more of, say, flexibility should you have in order to be fully compensated for a wage decrease of the magnitude of $5 \% ?^{7}$ When the wage coefficient is fixed, as in our application, then the mean $W t P$ for flexiility is computed as

$$
W t P_{\text {flexibility }}=\frac{b_{\text {flexibility }}}{\beta_{\text {wage }}} .
$$

We estimate mean and standard deviation of the $\mathrm{WtP}$ for all vignette attributes. However, to ease the computational burden, we only estimate mean effects of all interaction terms between vignette attributes and observable characteristics. ${ }^{8}$

\footnotetext{
${ }^{6}$ Importantly, the mixed logit model does not exhibit Independence of Irrelevant Alternatives (IIA).

${ }^{7}$ Technically, we simply differentiate equation (1) and set it equal to zero. Constant utility is then obtained by increasing the amount of at least one benefit while lowering the wage (provided all features of the package are considered "positive", which is the case here).

${ }^{8}$ In the Simulated $M L$ we used 100 repetitions.
} 


\section{Results}

We first present results from estimation of a simple conditional logit and compare these with parameter estimates from a mixed logit, see Models (1) and (2) in Table 4.

[Table 4 about here]

The mean coefficients of the mixed logit model are generally higher than the estimated parameters from the conditional logit model. ${ }^{9}$ The fact that the magnitude of the differences in many of the estimated parameters is about a factor of two indicates that the random parameters explain a lot of the variance in unobserved utility. Indeed, with the exception of "Bonus with $25 \%$ chance", we find that all random parameters are highly significant, and that their estimated coefficients are relatively high compared to their mean values.

All coefficients have the expected positive sign. ${ }^{10}$ This has the important implication that there indeed is a trade-off between the nonmonetary benefits and the wage.

One key advantage of vignettes is that respondents are faced with similar choice situations. However, in this study the vignettes describe fictive jobs and the wage is described relative (in percent) to the respondent's current wage. Answers to a question about the respondent's own wage subsequently enabled us to estimate the model. Obviously, this approach requires that we control for respondent's own wage. This is implemented by introducing an interaction term between each of the vignettes and an indicator for whether or not the respondent's own wage is above or below the median wage in our

\footnotetext{
${ }^{9}$ The unobserved variation contained in $\varepsilon_{n j t}$ is much larger in the logit model. Hence, in order to normalize $\varepsilon_{n j t}$ to have the appropriate variance of an extreme value distribution it has to be normalized by a higher value in the logit model compared to the mixed logit model. As the $\beta$-parameters are normalized by the same value as $\varepsilon$, this normalization explains the difference in the $\beta$ values in the two models.

${ }^{10}$ In Model (2) there is one exception in "Bonus with $50 \%$ chance", which is insignificant. Once we control for the respondent's own wage, as in Model (3), the coefficient for this parameter becomes positive and highly significant.
} 
sample, see Model (3) in Table $4 .{ }^{11}$ As expected, it is relevant to control for the respondent's own wage. Notably, flexibility, five days of training and pc + internet are valued significantly higher among respondents in the top half of the wage distribution. The increased log-likelihood also indicates a better fit of the data. ${ }^{12}$

The estimated random coeffcients are assumed to be normally distributed. This implies that, while most respondents may place a relatively high value on the various vignette attributes, there is a proportion of the respondents who place a negative value on the attribute. By definition, the assumption of normally distributed random coefficients yield WtP-estimates where the sign changes across the distribution of respondents since the normal distribution is defined from minus infinity to infinity. Alternatively, the random coefficients could be assumed to follow some other known distribution, like the log-normal distribution, which is defined from zero to infinity. Hence, with the log-normal assumption we impose a restriction that ensures that all individuals place a positive value on the attribute.

[Table 5 about here]

The results from this sensitivity analysis, see Table 5, indicate that both the mean value and the standard deviation change only little. In addition, the log-likelihood value is virtually constant. Although the log-normal assumption is appealing, it does not come without a cost. The lognormal distribution exacerbates the problem in the right-most part of the distribution (as it has a thicker upper tail). In addition, it is often very hard to obtain convergence with the log-normal assumption imposed. In the fol-

\footnotetext{
${ }^{11}$ Arguably, this is a rather crude manner to control for income. It is chosen here because it facilitates interpretation of the results. Introducing own wage as a continuous variable or using dummies for quantiles makes little difference.

${ }^{12}$ In all three models of Table 4 the coefficients are estimated under the assumption that they are independently and identically distributed. However, the simple mixed logit model in column (2) of Table 4 has also been estimated allowing for correlated random coefficients. This specification is much more computer-intensive and thus greatly increases the computational burden. The estimated mean coefficients (not shown) rise somewhat, which again reflects that this extension to the model captures more of the variance. However, the ratios between coefficients, the WtPs, change much less.
} 
lowing, we therefore continue with the assumption of normally distributed random coefficients but note that one needs to interpret the results with due caution, especially in the tails of the distribution. ${ }^{13}$

In the following, the specification of the model is extended with a series of observable covariates that intuitively one could think are linked to the utility of one or more of the nonmonetary goods described by the vignette attributes. Given the high number of parameters to be estimated we do not allow the coefficients to be correlated. ${ }^{14}$

\subsection{Willingness-to-Pay for Nonmonetary Job Attributes and Fringe Benefits}

One of the key insights from the hedonic utility model is that individuals differ in their valuation of nonmonetary rewards. We therefore extend the model specification by interaction terms between vignette characteristics and indicator variables for female, good physical health (self-reported), age 57 or above, children below age 6 in the household, low level of education, and an indicator variable for long commuting time between home and work. The estimated coefficients are given in Table B2 in the Appendix. All parameters for the vignette attributes have the expected signs, and are highly significant (with the exception of 2 days of training). Respondents value the vignette attributes very differently; most of the random coefficients are highly significant and have relatively high parameter values as compared to the corresponding mean estimates.

Based on the coefficients in Table B2 we can compute WtP for the vignette attributes; these are shown in Table 6.

[Table 6 about here]

\footnotetext{
${ }^{13}$ This precaution is necessary for any distribution one may chose. The basic issue is that an unrestricted distribution necessarily gives implausible results for some share of the population. This issue is described in detail by Revelt and Train (1998, footnote $14 \mathrm{pp}$. 655-656).

${ }^{14}$ The computational burden simply becomes insurmountable given the number of observations and the number of parameters.
} 
The mean WtP for both health packages and for both levels of flexibility is quite high. In particular, it is probably not realistic that respondents would be willing to pay almost 400 USD/month for "Some flexibility", although flexibility often is given a very high priority, Bender et al. (2005). ${ }^{15}$ It seems likely that there is some degree of "hypothetical bias" here, whereby respondents "offer" to pay more in hypothetical choice situations compared to their true preferences revealed through real out-of-pocket purchases, List (2001). ${ }^{16}$

However, having accounted for this possibility we may also note that the other parameter estimates appear quite plausible. For instance, the cost of internet (ADSL) and a home-pc would amount to about 100 USD/month, which is in line with our mean estimate, and the value of one month's bonus multiplied with the chance of receiving it is, on average, lower than our $25 \%$ estimate but higher than our $50 \%$ estimate.

One advantage of the mixed logit is that the willingness-to-pay can be given a graphical presentation, which facilitates interpretation and especially serves to underscore the importance of the entire distribution of WtPs. Figure 3 demonstrates that, while the mean $\mathrm{WtP}$ for flexibility is estimated to be around 400 USD per month, respondents do place very different values on flexibility, and the distribution consequently becomes very wide. Not surprisingly, the distribution is widest for the high level of flexibility. As one could expect, some employees value flexibility a lot while others pay little attention to this job characteristic. This is in line with the chessplayerwindsurfer argument given in Figure 1. We return to heterogeneity in the next section.

\section{[Figure 3 about here]}

As discussed above the normality assumption implies that a share of

\footnotetext{
${ }^{15}$ Given our selected sample of relatively high educated, the 400 USD corresponds to about $6 \%$ of the average earnings of 6400 USD. This appears very high.

16 "Hypothetical bias" is a well-known problem in the contingent valuation literature. It refers to the experience from several studies that individuals in hypothetical situations tend to bias their intentions upwards as compared to their choices in real action situations.
} 
the respondents have a WtP below zero. These shares are given in the second column of Table $6 .{ }^{17}$ Arguably, such shares have to be interpreted pragmatically and with caution as they are, at least to some degree, an outcome of the assumed normality.

\subsection{Heterogeneity in Individual Preferences}

In personnel economics models, the provision of benefits and nonmonetary job attributes is motivated by rational behavior and efficiency as firms are trying to attract the types of workers they desire. It is, therefore, of interest to examine how the willingness to pay for fringe benefits and job amenities varies across individuals with different observable characteristics.

The parameter estimates for several of the interaction-terms reveal significant differences in WtP for the fringe benefits and job amenities included in our model and most of them appear intuitively plausible. For instance, women value flexibility and employer provided training significantly higher than men, see Table 7 . This is in line with a general finding that women participate in training more often than men (Trepartsudvalget, 2006). Bender et al. (2005) also find that women value job flexibility considerably higher than men in terms of job satisfaction, possibly because greater flexibility facilitates balancing work and family life, which traditionally has received more attention from females than males, see Datta Gupta and Stratton (2010) for a recent time-use study among Danish couples.

[Table 7 about here]

Flexibility is also valued higher by high-wage earners, the older part of the workforce and by respondents who have children below 6 years of age. One could hypothesize that employees with relatively long commuting times also would value flexibility more. However, respondents in our sample generally commute relatively short spells (the 75 th percentile is 35 minutes) and

\footnotetext{
${ }^{17}$ Given the random coefficents are assumed normally distributed, the share below zero can be computed as $100-\Phi\left(\frac{b_{k}}{\sigma_{k}}\right)$, where $\Phi()$ denotes the cumulative standard normal distribution, $\mathrm{b}_{k}$ the mean estimate and $\sigma_{k}$ the estimated standard deviation.
} 
commuting time is not found to have a significant impact on respondents' $\mathrm{WtP}$ for any of the job amenities and fringe benefits. ${ }^{18}$

The elderly part of the workforce values bonuses and the possibility of having employer-provided home-pc and internet access significantly lower than their younger peers. Age, on the other hand, does not appear to have a significant impact on the value attributed to health packages or employer provided training. Especially the latter result is somewhat surprising as elderly workers cannot reap benefits from training over as many years as their younger colleagues. ${ }^{19}$

An employee characteristic which is not observed in our data, but is likely to influence individuals' choices of compensation packages, is risk aversion. A growing, mainly experimental literature has shown that females are on average more risk averse than males (Croson and Gneezy, 2009), and there is also evidence of risk aversion increasing with age (Barsky et al., 1997). According to the interaction term estimates there is no significant gender difference in the willingness to pay for bonuses. However, for the elderly respondents we do find that they value bonuses significantly less positively (in fact even negatively) than younger employees.

The observation that the older part of the work force does not value health insurance significantly higher than the average respondent is also somewhat surprising. Notice here that physical health is included as a control variable, and that "old" include respondents up to 64 years of age only.

Finally, we may note that the "less educated" in our sample, i.e., respondents with a short college degree or less, value the longest training significantly less than respondents with a higher education. This is consistent with lower returns to training among low educated as a result of complementarity in skill acquisition; see e.g., Cunha and Heckman (2007). Furthermore, highly educated individuals are likely to obtain more utility from time spent in training.

\footnotetext{
${ }^{18}$ Our threshold for "long commute" is defined as those above the $75^{t h}$ percentile.

${ }^{19}$ We also asked respondents about their expected age of retirement. This allows us to compute the expected number of years left in the work force. However, this also turned out to be completely unrelated to the $\mathrm{WtP}$ for training.
} 


\subsection{Compensation Packages as Sorting Devices}

A key insight from the personnel economics literature, see e.g., Lazear and Shaw (2007), is that fringe benefits and job amenities can be used by employers as an instrument for sorting employees. While the argument is intuitively persuasive, there is little empirical evidence to support it.

It is difficult to test for sorting also within the setup of this paper. However, we may find indications of sorting if, for instance, individuals who receive more training also are found to have a higher willingness to pay for training. In general, if sorting is important, we would expect to find that the WtP for a given benefit is higher among employees who currently receive the benefit in question than among those who do not.

[Table 8 about here]

We do find suggestive evidence of sorting, see Table 8. We compute the "Extra WTP" for individuals who receive a given benfit in their current job as the magnitude, in percent, of the estimate of the interaction term between the vignette attribute and an indicator variable for whether the individual is receiving the fringe benefit/job amenity in question in her current job. All interaction terms with the respondent's situation in her current job attach positive parameter estimates although not all of them differ significantly from zero. The indications of sorting only appear for relatively high levels of health insurance, flexibility and training. This is intuitively appealing since sorting arguably is more likely to arise if the magnitude of the fringe or amenity provided exceeds a certain threshold level.

It is important to emphasize that the results in Table 8 do not prove the occurrence of sorting. An alternative explanation may be that in certain occupations it simply does not make sense to provide an employee with a home pc and internet to perform the job tasks (a bus driver for example). In this case, it would be erroneous to conclude that the differences in WtP indicate that employees actually sorted, since "sorting" allude to the idea that they chose their current job over another "similar" job, which did not offer the benefit or job attribute in question. 
In order to investigate this a bit further we re-estimate the model for specific sub-samples. Most job openings relevant to our selected sample of respondents would include some degree of flexibility and some amount of on-the-job training. However, "pc + internet" and the health packages are mainly offered to specific groups.

First, it is likely that individuals with relatively low levels of education are in jobs where the use of home pc and internet connection is of little relevance. Such employees likely place a lower value on home pc and internet as a fringe benefit and in addition, they are less likely to have been offered such a compensation package. Indeed, when estimating the model on a sub-sample of respondents with at minimum some college education, the difference from the average WtP-estimates for "pc + internet" drops from an extra $307 \%$ (Table 8) to $141 \%$. This remains a very high increased willingness to pay. Sorting may explain some of this difference.

Second, the use of health packages is very common in the private sector, but not in the public sector. In our sample, $3 \%$ of the public sector employees state that they receive some type of health package. The corresponding number among private sector workers is $64 \%$. Hence, signs of sorting should mainly be found by comparing private sector workers with some type of health package in their current job to other private sector workers with no health package in their current job. This comparison yields a difference in the willingness to pay for the large health package of $26 \%$, compared to $44 \%$ in Table 8. The difference remains insignificant for the small health package. Albeit no ultimate proof, the sub-sample estimates still provide indications of sorting.

\section{Discussion}

Our mixed logit analysis shows that there are fairly large differences between individuals in how they value various fringe benefits and that there are clear trade-offs between wages and fringes as predicted by hedonic wage theory. Moreover, we find that the willingness to pay for specific fringe benefits differ between demographic groups. For instance, females, employees 
with children under school age and elderly workers place a higher value on working time flexibility. Obviously, this has some implications both for policies for balancing work and family life as well as for increasing labor force participation among elderly workers.

Furthermore, when there is a choice between different quantities of the fringe benefit, the difference in willingness to pay for the larger quantity does not - save training - differ from that for the smaller quantity. This may be interpreted as indicating that the benefits to some extent are conceived of as gifts or as signals that the employer is concerned about them and the employees are willing to reciprocate by paying for them; see e.g., Baron and Kreps (1999), pp. 302ff, for a discussion. Note, that the notion of a benefit as a gift depends crucially on which motives the employer is considered to have for providing them. Unlike training, which is likely to be considered by the employee to benefit the firm more directly, working time flexibility and a health insurance package are conceived of as meeting special needs of the employee, and therefore, the willingness to pay for them does not vary with the amount offered.

The considerable heterogeneity in individuals' tastes for the various fringe benefits could be interpreted as support for use of cafeteria-style compensation plans, according to which the employee can choose between a number of benefits within a given budget set in advance by the employer. However, use of cafeteria plans makes it difficult for employers to utilize fringe benefits as an employee sorting device. Our analysis in section 5.3 above provides some suggestive evidence of employers using fringe benefits as a means of sorting workers. This in line with Oyer (2008) who looks at whether employees likely to value a fringe benefit are more likely to also receive it, whereas we compare the employee's willingness to pay for a benefit with its presence in her actual compensation package. Our result underscores that sorting is more than a theoretical construct and that indeed, people do respond to nonmonetary rewards.

The vignettes method also has the potential advantage that it can be used not only for research but also has a potential for helping employers in designing compensation packages for their employees. However, as our exer- 
cise has demonstrated the method also has a number of potential limitations worth pointing out. One is that the number of mixed parameters to be estimated has to be kept fairly low otherwise the computational burden grows very fast. A weakness of the method one needs to be aware of is that the estimates may be upward biased because of the hypothetical bias problem. However, relative valuations between types of nonmonetary rewards as well as between individuals with varying characteristics should not be affected by such bias. Our results concur with this rationale as they generally show the expected relative differences.

\section{Conclusion}

Previous studies of fringe benefits have focused primarily on the cost side. The idea is that when the employer can acquire the fringe goods cheaper than the employees or when they are associated with a tax arbitrage, the likelihood that the value of a fringe benefit to an employee exceeds the firm's costs of providing it is higher. The focus in this paper differs insofar that we examine directly individuals' valuations of the fringe benefits by estimating their willingness to pay for them.

For this purpose we make use of a method, building vignettes and merging them with survey data, which is new within this area of research. This allows us to solve some of the problems that have plagued the earlier literature, like unobserved heterogeneity in ability, differences in tastes for different fringe benefits and the selectivity due to non-randomness of job changes.

All in all, our findings lend strong support to a key notion in the economic analysis of employment relationships, that nonmonetary job attributes can be monetized. As emphasized by Lazear and Shaw (2007) this is important as it implies that any model in personnel economics can be applied to nonmonetary as well as monetary rewards. For instance, the tournament model, whereby the possibility of future promotions and wage increases induce lower ranked workers to perform better, also applies to status and prestige, not only monetary rewards. Moreover, this paper has shown the potential of 
the vignettes method in measuring willingness-to-pay for job attributes in contexts where conventional data collection is difficult, if not impossible. 


\section{References}

Adamowicz, W., P. Boxall, M. Williams, and J. Louviere (1998): Stated Preference Approaches for Measuring Passive Use Values: Choice Experiments and Contingent Valuation. American Journal of Agricultural Economics, 80(1), 64-75.

Baron, J.N. \& D.M. Kreps (1999): Strategic human resources : frameworks for general managers. John Wiley \& Sons, Inc.

Barsky, R. B., T. F. Juster, M. S. Kimball \& M. D. Shapiro (1997): Preference Parameters and Behavioral Heterogeneity: An Experimental Approach in the Health and Retirement Survey. Quarterly Journal of Economics, 112, 537-578.

Ben-Akiva, M., D. Bolduc and M. Bradley (1993): Estimation of Travel Choice Models with randomly Distributed Values of Travel Time. Transportation Research Record, 1413, 88-97.

Bender, K.A., S.M. Donohue and J.S. Heywood (2005): Job Satisfaction and Gender Segregation. Oxford Economic Papers, 57, 479-496.

Brown, C. (1980): Equalizing Differences in the Labor Market. Quarterly Journal of Economics, 94(1), 113-134.

Croson, R. \& U. Gneezy (2009): Gender Differences in Preferences. Journal of Economic Literature, 47(2), 448-474.

Cunha, F. \& J.J. Heckman (2007): The Technology of Skill Formation. American Economic Review, $\mathbf{9 7}(2), 31-47$.

Datta Gupta, N. \& L. Stratton (2010): Examining the Impact of Alternative Power Measures on Individual Time Use in American and Danish Couple 
Households. Review of Economics of the Household, 8, 325-343.

Duncan, G. \& B. Holmlund (1983): Was Adam Smith Right After All. Another Test of the Theory of Compensating Wage Differentials. Journal of Labor Economics, 1(4), 366-379.

Eriksson, T. (2010): Firm Type and HRM Policy Differences. Mimeo.

European Company Survey (2009). Eurofond, Dublin.

Gneezy, U. \& A. Rustichini (2000): Pay Enough or Don't Pay at All. Quarterly Journal of Economics, 115(3), 791-810.

Green, P.E. and V. R. Rao (1971): Conjoint Measurement for Quantifying Judgmental Data. Journal of Marketing Research, 8(3), 355-363.

Green, P.E. \& V. Srinivasan (1978): Conjoint Analysis in Consumer Research: Issues and Outlook. Journal of Consumer Research, 5, 103-123.

Gronberg, T \& Reed, W. (1994): Estimating Workers' Marginal Willingness to Pay for Job Attributes Using Duration Data. Journal of Human Resources, 29(3), 911-933.

Lazear, E.P. (1995): Personnel Economics. The Wicksell Lectures, MIT Press.

Lazear, E. P. (1998): Personnel Economics for Managers. Wiley.

Lazear, E. P. \& K. Shaw (2007): Personnel Economics: The Economist's View of Human Capital. Journal of Economic Perspectives, 21(4), 91-114.

Lazear, E. P. \& P. Oyer (2010): Personnel Economics. Forthcoming in: R. Gibbons and J. Roberts (eds.), Handbook of Organizational Economics. 
North-Holland, Amsterdam.

List, J. A. (2001): Do Explicit Warnings Eliminate the Hypothetical Bias in Elicitation Procedures? Evidence from Field Auctions for Sportscards. American Economic Review, 91(5), 1498-1507.

Milkovich, G. \& J. Newman (2010): Compensation, McGraw-Hill.

Oyer, P. (2008): Salary or Benefits? Research in Labor Economics, 28, 429467.

Oyer, P. \& S. Schaefer (2010): Personnel Economics: Hiring and Incentives. Forthcoming in: O. Ashenfelter and D. Card (eds.), Handbook of Labor Economics, Volume 4. North-Holland, Amsterdam.

Revelt, D. \& K. Train (1998): Mixed Logit with Repeated Choices: Households' Choice of Appliance Efficiency Level. Review of Economics and Statistics, LXXX(4), 647-657.

Rosen, S. (1974): Hedonic Prices and Implicit Markets: Product Differentiation in Pure Competition. Journal of Political Economy, 82 (January/February), 34-55.

Salop, J. \& S. Salop (1976): Self-Selection and Turnover in the Labor Market. Quarterly Journal of Economics, 90, 619-627.

Stern, S. (2004): Do Scientists Pay to be Scientists? Management Science, 50 (June), 835-853.

Train, K. (2003): Discrete Choice Methods with Simulation. Cambridge; Cambridge University Press.

Trepartsudvalget (2006): Livslang opkvalificering og uddannelse for alle på 
arbejdsmarkedet - Rapport fra trepartsudvalget, Bind 1 og 2. (In Danish).

Van Beek, K. W. H., C. C. Koopmans \& B. M. S. van Praag (1997): Shopping at the Labour Market: A Real Tale of Fiction. European Economic Review, 41, 295-317. 
Figure 1 Heterogeneous Preferences

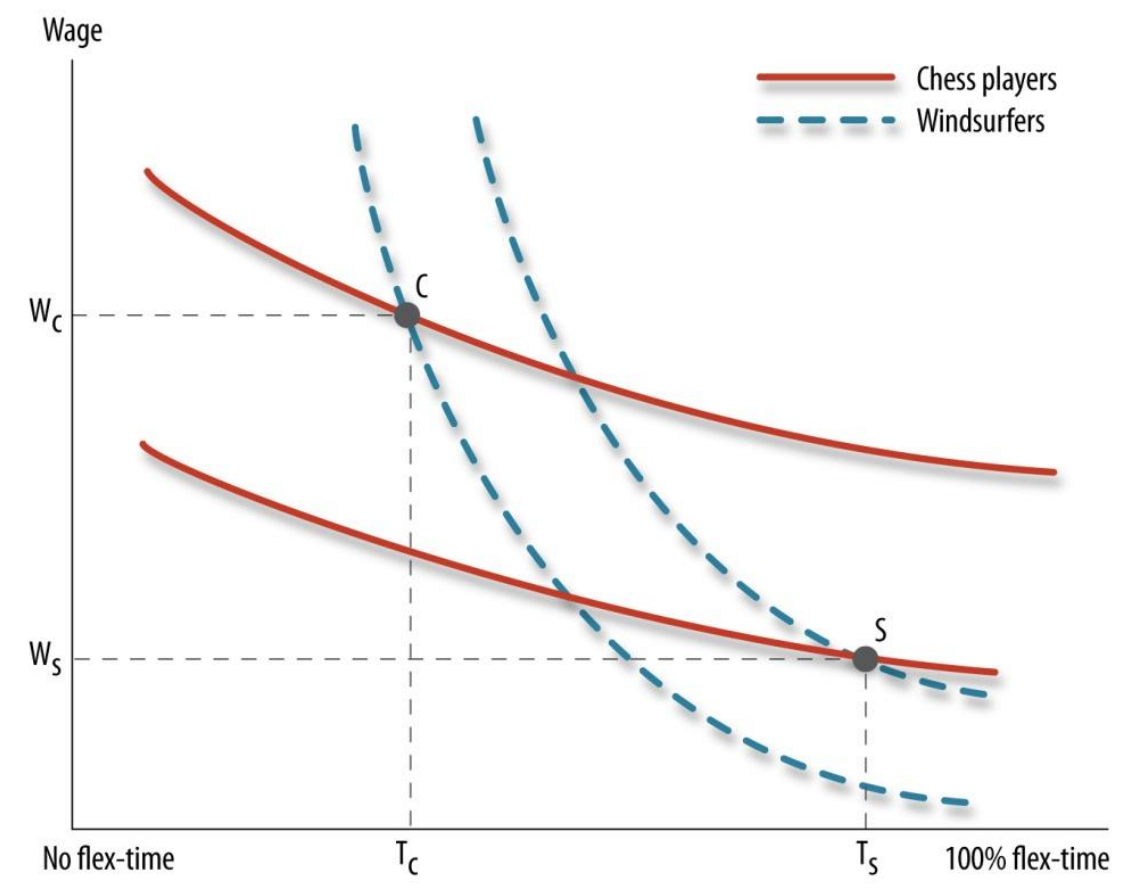


Figure 2 Vignette Example

\begin{tabular}{|c|c|c|}
\hline & Job A & Job B \\
\hline Home-pc + ADSL internet & Yes & Yes \\
\hline Work related training & No continuous training & Yes, 5 days/year \\
\hline Health insurance & $\begin{array}{l}\text { Complete insurance including access to } \\
\text { operation and medical specialist }\end{array}$ & No health insurance is offered \\
\hline Work hours flexibility & $\begin{array}{l}\text { Work hours are decided by the company } \\
\text { with no possibility for changes }\end{array}$ & $\begin{array}{l}\text { You may freely decide on your work } \\
\text { hours }\end{array}$ \\
\hline $\begin{array}{l}\text { Annual bonus (equivalent to } \\
\text { one month's pay) }\end{array}$ & No chance of bonus & No chance of bonus \\
\hline Monthly wage before tax & As in current job & As in current job $+5 \%$ \\
\hline
\end{tabular}

Which job-compensation package do you prefer? A or B? 
Table 1 Frequency distribution of bonuses in respondent's current job

\begin{tabular}{lcc}
\hline & Frequency & Percent \\
\hline Yes, equivalent to less than 5\% of annual salary & 452 & 14.6 \\
Yes, equivalent to between 5 and 10\% of annual salary & 222 & 7.2 \\
Yes, equivalent to more than 10\% of annual salary & 127 & 4.1 \\
No, I did not receive any bonus or the like & 2,270 & 73.4 \\
Don't know & 23 & 0.7 \\
\hline
\end{tabular}

Table 2 Frequency distribution of fringe benefits, 2008

\begin{tabular}{lcc}
\hline & & \\
Received & Frequency & Percent \\
\hline No fringe benefits & 581 & 18.8 \\
& & \\
Health insurance & 1,079 & 34.9 \\
Internet and pc & 820 & 26.5 \\
Free telephone & 572 & 18.5 \\
Free fruit & 1,593 & 51.5 \\
Free coffee & 2,024 & 65.4 \\
Company car & 124 & 4.0 \\
Membership of fitness club or similar & 235 & 7.6 \\
Don't know & 37 & 1.2 \\
Other & 367 & 11.9 \\
\hline
\end{tabular}

Note: The question read: "Which fringe benefits did you receive in 2008 in relation to your main occupation?"

Table 3 Amount of continuous training paid by employer, 2008

\begin{tabular}{lcc}
\hline & Frequency & Percent \\
\hline Yes, up to 5 working days & 1,050 & 33.9 \\
Yes, 5-10 working days (1-2 weeks) & 442 & 14.3 \\
Yes, 11-20 working days (2-4 weeks) & 194 & 6.3 \\
Yes, 21-60 working days (1-3 months) & 84 & 2.7 \\
Yes, 61 working days or more (more than 3 months) & 23 & 0.7 \\
No, but I have previously attended training courses & 792 & 25.6 \\
No, I have never attended any training & 477 & 15.4 \\
Don't know & 32 & 1.0 \\
\hline
\end{tabular}

Note: The question read: "Did you in 2008 participate in any training paid by your employer, and if yes how long did the training last? (If more than one training spell, please state the total duration of training days in 2008)". 
Table 4 Results from Logit and Mixed logit models

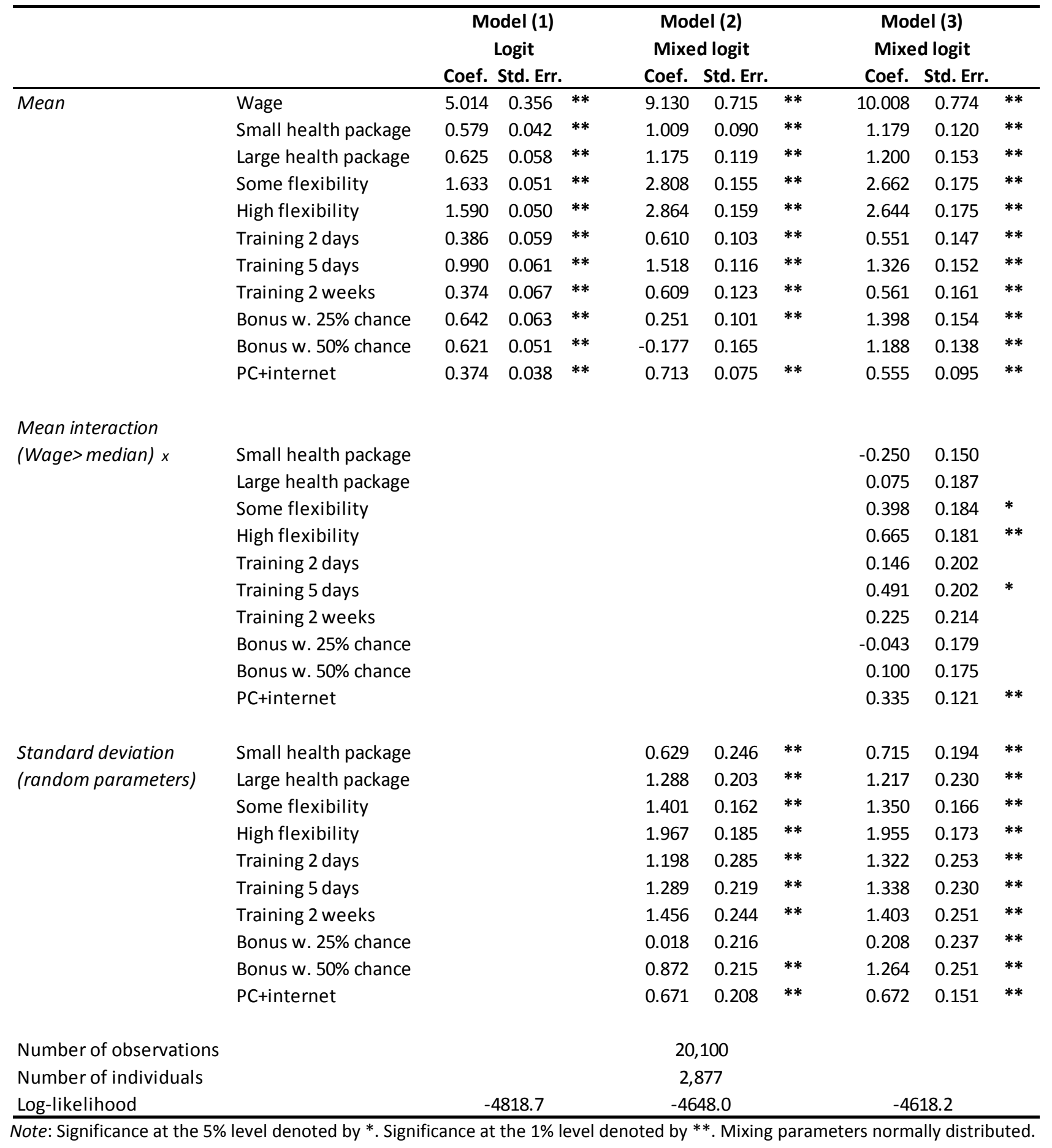


Table 5 WtP for Bonus using different distributional assumptions for the mixing distribution

\begin{tabular}{lccc}
\hline & & Normal & Log-normal \\
\hline Mean & Bonus 25 & 256 & 254 \\
& Bonus 50 & 217 & 228 \\
\multirow{2}{*}{ Standard Deviation } & & & \\
& Bonus 25 & 38 & 42 \\
& Bonus 50 & 231 & 266 \\
Log-likelihood & & & -4618.0 \\
\hline
\end{tabular}

Note: The estimated model is Model (3) in Table 4.

Table 6 Willingness to Pay (in USD) for Vignette Attributes, Mean Estimates and Share Below Zero

\begin{tabular}{lcc}
\hline & WtP (USD) & \% below zero \\
\hline Small health package & 189 & $0 \%$ \\
Large health package & 189 & $21 \%$ \\
Some flexibility & 394 & $7 \%$ \\
High flexibility & 403 & $13 \%$ \\
Training 2 days & 63 & $40 \%$ \\
Training 5 days & 245 & $13 \%$ \\
Training 2 weeks & 106 & $31 \%$ \\
Bonus w. 25\% chance & 243 & $0 \%$ \\
Bonus w. 50\% chance & 240 & $15 \%$ \\
PC+internet & 112 & $20 \%$ \\
\hline
\end{tabular}

Note: The share below zero is set to $0 \%$ in the two cases where the random coefficient was insignificant. 
Figure 3 Distribution of Willingness-to-Pay for Flexibility

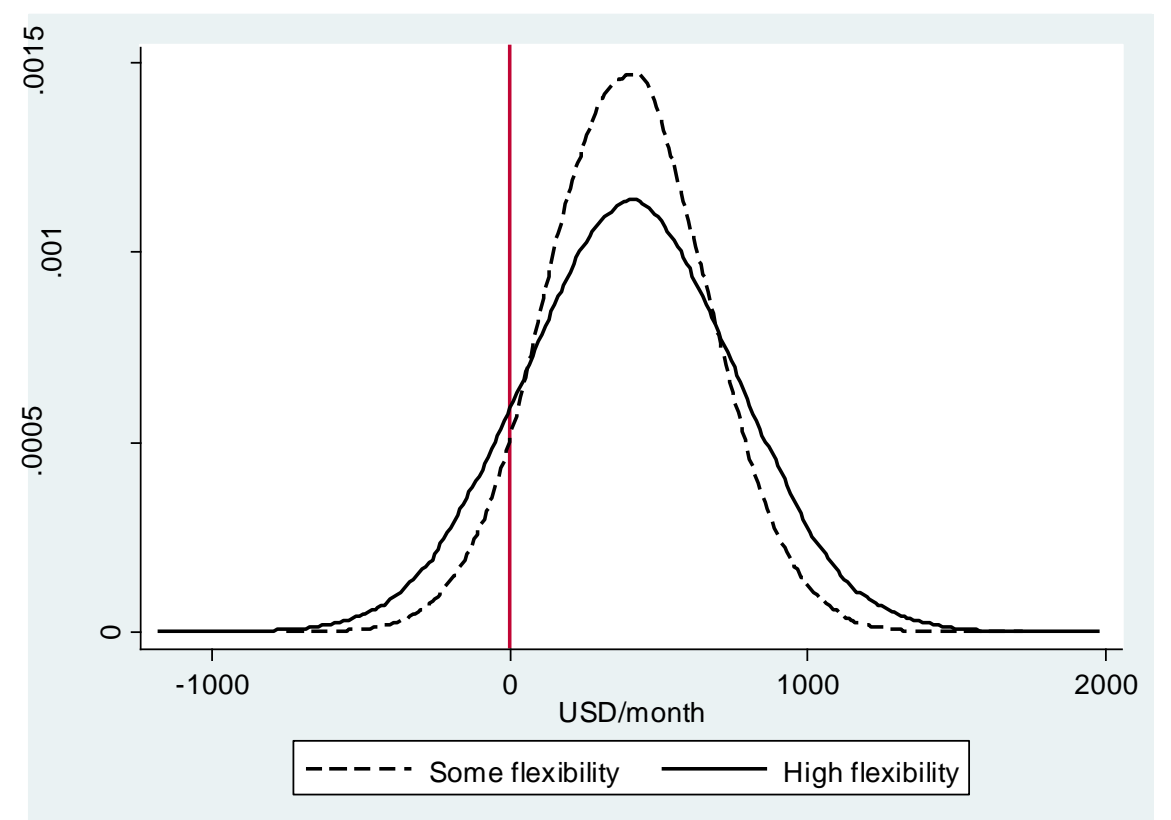

Note: The Figure is based on simulations with 10,000 draws from a normal distribution using the estimation results given in Table 6. 
Table 7 Difference from mean Willingness to Pay Estimates across Observables, in percent

\begin{tabular}{|c|c|c|c|c|c|c|c|}
\hline & (1) & (2) & (3) & (4) & (5) & (6) & (7) \\
\hline & Wage>median & Female & $\begin{array}{l}\text { Good physical } \\
\text { health }\end{array}$ & Age 57 or above & $\begin{array}{l}\text { Family w child } \\
\text { below age } 6\end{array}$ & Low education & $\begin{array}{l}\text { Long commute } \\
\text { (35 mint) }\end{array}$ \\
\hline \multicolumn{8}{|l|}{ Small health package } \\
\hline Large health package & & & $-43 \%$ & & & $48 \%$ & \\
\hline Some flexibility & $21 \%$ & $25 \%$ & & $181 \%$ & $12 \%$ & & \\
\hline High flexibility & $29 \%$ & $28 \%$ & & & $9 \%$ & & \\
\hline Training 2 days & & $128 \%$ & & & & & \\
\hline Training 5 days & & $33 \%$ & & & & & \\
\hline Training 2 weeks & & $81 \%$ & & & & $-81 \%$ & \\
\hline \multicolumn{8}{|l|}{ Bonus w. $25 \%$ chance } \\
\hline Bonus w. $50 \%$ chance & & & & $-46 \%$ & & & \\
\hline PC+internet & $52 \%$ & & & $-89 \%$ & & & \\
\hline
\end{tabular}

Note: Only differences significant at the $5 \%$ level are reported. 
Table 8 Differences in Mean Willingness-to-Pay by Characteristics of Current Job, in percent

\begin{tabular}{lcl}
\hline Vignette attribute & Extra WtP & \multicolumn{1}{c}{ Conditioning on current job } \\
\hline $\begin{array}{l}\text { Small health package } \\
\text { Large health package }\end{array}$ & -- & $\begin{array}{l}\text { Some health package provided in current job } \\
\text { Some health package provided in current job }\end{array}$ \\
\hline Some flexibility & $44 \%$ & $\begin{array}{l}\text { Work hours in current job are shifting after } \\
\text { agreement between employer and employee } \\
\text { Work hours in current job are shifting from day } \\
\text { to day by respondent's own choice }\end{array}$ \\
High flexibility & -- & $\begin{array}{l}\text { Respondent received 1-4 days of training in } \\
2008\end{array}$ \\
\hline Training 2 days & -- & $\begin{array}{l}\text { Respondent received 5-60 days of training in } \\
2008\end{array}$ \\
Training 5 days & $57 \%$ & $\begin{array}{l}\text { Respondent received 5-60 days of training in } \\
2008\end{array}$ \\
Training 2 weeks & $229 \%$ & $\begin{array}{l}\text { Respondent received bonus in 2008 } \\
\text { Respondent received bonus in 2008 }\end{array}$ \\
\hline Bonus w. 25\% chance & -- & Respondent received PC+internet in 2008 \\
Bonus w. 50\% chance & -- & $307 \%$
\end{tabular}

Note: The "Extra WtP" is the magnitude, in percent, of the estimate of the interaction term between the vignette attribute and an indicator variable for whether the individual is receiving the fringe benefit/job amenity in question in her current job. Only differences significant at the $5 \%$ level are reported. Altering the condition for bonus to respondents who receive a relatively high bonus does not yield a significant difference. Other combinations of training days make no qualitative difference either. 


\section{Appendix A: Details on the Vignettes}

The introductory text reads:

"Assume that you for one reason or another have you stop at your current job and have to look for a new job.

Assume furthermore, that you in a relatively short time receive several job offers. These will subsequently be shown on the screens. These job offers do not differ from you current job except for certain features which are emphasized.

You are asked to compare job offer $A$ (to the left) with job offer B (to the right) and to choose the one that you prefer. There are no "right" or "wrong" answers - you should only choose the one of the two you like better (even if you may not like any of them)"

Table A1 Possible values of vignette attributes

\begin{tabular}{|c|c|}
\hline Attribute & Possible Values \\
\hline Home-pc + ADSL internet & $\begin{array}{l}- \text { Yes } \\
- \text { No }\end{array}$ \\
\hline Work related training & $\begin{array}{l}\text {-No continuous training } \\
\text {-Yes, } 2 \text { days/year } \\
\text {-Yes, } 5 \text { days/year } \\
\text {-Yes, } 10 \text { days/year }\end{array}$ \\
\hline Health insurance & $\begin{array}{l}\text {-No health insurance is offered } \\
\text {-Access to a few free consultations at medical specialist including psycologist } \\
\text {-Complete insurance including access to operation and medical specialist }\end{array}$ \\
\hline Work flexibility & $\begin{array}{l}\text {-Work hours are decided by the company with no possibility for changes } \\
\text {-You may choose your work hours within certain limits } \\
\text {-You may freely decide on your work hours }\end{array}$ \\
\hline $\begin{array}{l}\text { Annual bonus (equivalent to } \\
\text { one month's pay) }\end{array}$ & $\begin{array}{l}\text {-No chance of bonus } \\
\text {-Yes, with } 25 \% \text { chance } \\
\text {-Yes, with } 50 \% \text { chance }\end{array}$ \\
\hline Monthly wage before tax & $\begin{array}{l}-A s \text { in current job } \\
-A s \text { in current job }+/-5 \% \\
- \text { As in current job }+/-10 \% \\
- \text { As in current job }+/-15 \%\end{array}$ \\
\hline
\end{tabular}


Appendix B: Additional Tables

Table B1 Means and Min/Max of Background Variables

\begin{tabular}{|c|c|c|c|}
\hline & \multicolumn{2}{|l|}{ Share (in \%) } & \multirow[b]{2}{*}{ Max } \\
\hline & or Mean & Min & \\
\hline Female & 50.7 & 0 & 1 \\
\hline \multicolumn{4}{|l|}{ Education } \\
\hline high school & 10.0 & 0 & 1 \\
\hline vocational education (carpenter etc) & 21.3 & 0 & 1 \\
\hline short term college (<3 years) & 15.6 & 0 & 1 \\
\hline medium term college (3-4 years) & 33.1 & 0 & 1 \\
\hline university ( 5 years or more) & 20.1 & 0 & 1 \\
\hline Monthly gross income (DKK) & 34,918 & 2,500 & $2,000,000$ \\
\hline Monthly gross income (USD) & 6,390 & 458 & 366,028 \\
\hline Married/cohab & 76.0 & 0 & 1 \\
\hline \multicolumn{4}{|l|}{ Number of children below 6 years of age } \\
\hline 0 children & 77.9 & 0 & 1 \\
\hline 1 child & 14.0 & 0 & 1 \\
\hline 2 children & 6.8 & 0 & 1 \\
\hline 3 children & 1.2 & 0 & 1 \\
\hline 4 children or more & 0.2 & 0 & 1 \\
\hline \multicolumn{4}{|l|}{ Number of children 6 years or older } \\
\hline 0 children & 65.2 & 0 & 1 \\
\hline 1 child & 17.6 & 0 & 1 \\
\hline 2 children & 13.8 & 0 & 1 \\
\hline 3 children & 3.2 & 0 & 1 \\
\hline 4 children or more & 0.2 & 0 & 1 \\
\hline \multicolumn{4}{|l|}{ Urbanization } \\
\hline country-side & 12.3 & 0 & 1 \\
\hline$<10,000$ inhabs & 20.4 & 0 & 1 \\
\hline $10,000-49,999$ inhabs & 24.9 & 0 & 1 \\
\hline $50,000-99,999$ inhabs & 12.8 & 0 & 1 \\
\hline 100,000 or more inhabs & 28.6 & 0 & 1 \\
\hline Age & 43.4 & 25 & 64 \\
\hline Years of labor market experience & 19.8 & 0 & 48 \\
\hline Years of tenure at current employer & 9.2 & 0 & 44 \\
\hline Years of tenure in current position & 5.8 & 0 & 41 \\
\hline Union member & 82.6 & 0 & 1 \\
\hline \multicolumn{4}{|l|}{ Hours worked per week } \\
\hline according to contract & 36.5 & 30 & 70 \\
\hline in reality & 39.1 & 30 & 73 \\
\hline
\end{tabular}




\begin{tabular}{|c|c|c|c|}
\hline (Table B1 continued) & $\begin{array}{c}\text { Share (in \%) } \\
\text { or Mean }\end{array}$ & Min & Max \\
\hline \multicolumn{4}{|l|}{ Sector } \\
\hline private & 57.0 & 0 & 1 \\
\hline governmental (public) & 12.8 & 0 & 1 \\
\hline regional/municipality (public) & 30.2 & 0 & 1 \\
\hline Minutes to commute home-work & 27.5 & 1 & 240 \\
\hline \multicolumn{4}{|l|}{ Firm Size (workplace) } \\
\hline less than 10 employees & 10.7 & 0 & 1 \\
\hline 10-24 employees & 14.3 & 0 & 1 \\
\hline 25-99 employees & 28.0 & 0 & 1 \\
\hline 100-499 employees & 25.0 & 0 & 1 \\
\hline 500 employees or more & 22.0 & 0 & 1 \\
\hline
\end{tabular}

Table B2 Parameter estimates for mixed logit model with interactions

\begin{tabular}{|c|c|c|c|c|}
\hline & & Coef. & Std. Err. & \\
\hline \multirow[t]{11}{*}{ Mean } & Wage & 10.234 & 0.781 & $* *$ \\
\hline & Small health package & 1.055 & 0.221 & $* *$ \\
\hline & Large health package & 1.057 & 0.283 & $* *$ \\
\hline & Some flexibility & 2.203 & 0.258 & $* *$ \\
\hline & High flexibility & 2.252 & 0.250 & $* *$ \\
\hline & Training 2 days & 0.355 & 0.270 & \\
\hline & Training 5 days & 1.368 & 0.265 & $* *$ \\
\hline & Training 2 weeks & 0.592 & 0.283 & $* *$ \\
\hline & Bonus w. $25 \%$ chance & 1.359 & 0.254 & $* *$ \\
\hline & Bonus w. $50 \%$ chance & 1.344 & 0.233 & $* *$ \\
\hline & PC+internet & 0.626 & 0.165 & $* *$ \\
\hline \multirow[t]{10}{*}{$S D$} & Small health package & 0.163 & 0.360 & \\
\hline & Large health package & 1.296 & 0.200 & $* *$ \\
\hline & Some flexibility & 1.504 & 0.166 & $* *$ \\
\hline & High flexibility & 1.969 & 0.179 & $* *$ \\
\hline & Training 2 days & 1.419 & 0.234 & $* *$ \\
\hline & Training 5 days & 1.186 & 0.249 & $* *$ \\
\hline & Training 2 weeks & 1.238 & 0.252 & $* *$ \\
\hline & Bonus w. $25 \%$ chance & 0.381 & 0.245 & \\
\hline & Bonus w. $50 \%$ chance & 1.289 & 0.250 & $* *$ \\
\hline & PC+internet & 0.755 & 0.132 & $* *$ \\
\hline
\end{tabular}

(continued next page) 


\begin{tabular}{|c|c|c|c|c|}
\hline \multicolumn{2}{|c|}{ Interaction terms with observables (mean) } & \multirow{2}{*}{$\begin{array}{c}\text { Coef. } \\
-0,167\end{array}$} & \multirow{2}{*}{\multicolumn{2}{|c|}{ Std. Err. }} \\
\hline (Wage > median) $x$ & Small health package & & & \\
\hline & Large health package & 0,257 & 0,207 & \\
\hline & Some flexibility & 0,455 & 0,203 & $* *$ \\
\hline & High flexibility & 0,650 & 0,196 & $* *$ \\
\hline & Training 2 days & 0,299 & 0,224 & \\
\hline & Training 5 days & 0,457 & 0,218 & $* *$ \\
\hline & Training 2 weeks & 0,247 & 0,235 & \\
\hline & Bonus w. $25 \%$ chance & $-0,042$ & 0,196 & \\
\hline & Bonus w. $50 \%$ chance & 0,082 & 0,187 & \\
\hline & PC+internet & 0,328 & 0,132 & $* *$ \\
\hline \multirow{10}{*}{ Female $x$} & Small health package & 0,217 & 0,155 & \\
\hline & Large health package & 0,082 & 0,198 & \\
\hline & Some flexibility & 0,546 & 0,195 & $* *$ \\
\hline & High flexibility & 0,626 & 0,189 & $* *$ \\
\hline & Training 2 days & 0,454 & 0,215 & $*$ \\
\hline & Training 5 days & 0,454 & 0,208 & $*$ \\
\hline & Training 2 weeks & 0,481 & 0,223 & $*$ \\
\hline & Bonus w. $25 \%$ chance & $-0,024$ & 0,187 & \\
\hline & Bonus w. $50 \%$ chance & 0,105 & 0,180 & \\
\hline & PC+internet & $-0,014$ & 0,126 & \\
\hline \multirow[t]{2}{*}{ Good physical health $x$} & Small health package & 0,033 & 0,137 & \\
\hline & Large health package & $-0,458$ & 0,195 & $*$ \\
\hline \multirow[t]{10}{*}{ Age 57 or above $x$} & Small health package & $-0,153$ & 0,243 & \\
\hline & Large health package & 0,392 & 0,312 & \\
\hline & Some flexibility & 0,760 & 0,309 & $*$ \\
\hline & High flexibility & 0,438 & 0,307 & \\
\hline & Training 2 days & $-0,137$ & 0,323 & \\
\hline & Training 5 days & 0,137 & 0,312 & \\
\hline & Training 2 weeks & 0,011 & 0,334 & \\
\hline & Bonus w. $25 \%$ chance & 0,110 & 0,291 & \\
\hline & Bonus w. $50 \%$ chance & $-0,623$ & 0,292 & $*$ \\
\hline & PC+internet & $-0,472$ & 0,203 & $*$ \\
\hline
\end{tabular}

(continued next page) 


\begin{tabular}{llcc} 
(Table B2 continued) & & Coef. & Std. Err. \\
\hline Child below age $6 x$ & Small health package & $-0,063$ & 0,074 \\
& Large health package & 0,081 & 0,096 \\
& Some flexibility & $\mathbf{0 , 2 6 2}$ & $\mathbf{0 , 0 9 6}$
\end{tabular} **

Note: Significance at the $5 \%$ level denoted by *. Significance at the $1 \%$ level denoted by **. Mixing parameters normally distributed. 